Analysis and Applications - ISAAC 2001 
International Society for Analysis, Applications and Computation

Volume 10

Managing Editor

Robert P. Gilbert

University of Delaware, U.S.A.

Advisory Board

Heinrich Begehr

Freie Universität, Berlin, Germany

Alain Bourgeat

University of Lyon, France

Antonio Fasano

University of Firenze, Italy

Man-Wah Wong

York University, Toronto, Canada

The titles published in this series are listed at the end of this volume. 


\section{Analysis and Applications - ISAAC 2001}

Edited by

Heinrich G.W. Begehr

Freie Universität Berlin, Berlin, Germany

Robert P. Gilbert

University of Delaware, Newark, DE, U.S.A.

and

Man Wah Wong

York University, Toronto, Canada

SPRINGER-SCIENCE+BUSINESS MEDIA, B.V. 
A C.I.P. Catalogue record for this book is available from the Library of Congress.

ISBN 978-1-4419-5247-9

ISBN 978-1-4757-3741-7 (eBook)

DOI 10.1007/978-1-4757-3741-7

Printed on acid-free paper
All Rights Reserved
(c) 2003 Springer Science+Business Media Dordrecht
Originally published by Kluwer Academic Publishers in 2003
No part of this work may be reproduced, stored in a retrieval system, or transmitted in any form or by any means, electronic, mechanical, photocopying, microfilming, recording or otherwise, without written permission from the Publisher, with the exception of any material supplied specifically for the purpose of being entered and executed on a computer system, for exclusive use by the purchaser of the work. 


\section{TABLE OF CONTENTS}

Preface $\ldots \ldots \ldots \ldots \ldots \ldots \ldots \ldots \ldots \ldots \ldots \ldots \ldots \ldots \ldots \ldots \ldots \ldots$ vii

1. Decay and computability $\ldots \ldots \ldots \ldots \ldots \ldots \ldots \ldots \ldots, 1$

I. Antoniou, Z. Suchanecki

2. Differential and pseudo-differential operators on graphs as models of mesoscopic systems $\ldots \ldots \ldots \ldots \ldots \ldots \ldots \ldots \ldots$

P. Kuchment

3. Homogenization of some multiparametric problems ... 31 N.S. Bakhvalov, M.E. Eglit

4. Power geometry as a new calculus $\ldots \ldots \ldots \ldots \ldots \ldots \ldots$. 51 A.D. Bruno

5. A survey of $Q$-spaces and $Q^{\#-\text { classes } \ldots \ldots \ldots \ldots \ldots .} 73$

M. Essén

6. Hyperbolically convex functions $\ldots \ldots \ldots \ldots \ldots \ldots \ldots, 89$

D. Mejía, Ch. Pommerenke

7. Nevanlinna theory in characteristic $P$ and applications 97 A. Boutabaa, A. Escassut

8. A new property of meromorphic functions and its applications $\ldots \ldots \ldots \ldots \ldots \ldots \ldots \ldots \ldots \ldots \ldots \ldots \ldots . \ldots \ldots$

G.A. Barsegian, C.C. Yang

9. Complex zero decreasing sequences and the Riemann

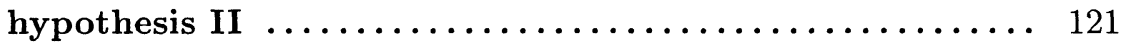

G. Csordas

10. Theory of reproducing kernels $\ldots \ldots \ldots \ldots \ldots \ldots \ldots, 135$

S. Saitoh 
$\mathrm{vi}$

11. Analytic functions and analytic functionals on some balls in the complex Euclidean space ................ 151

K. Fujita, M. Morimoto

12. Batteries and energy minimization problems ...... 161 P.M. Tamrazov

13. Vector-valued extentions of some classical theorems in harmonic analysis $\ldots \ldots \ldots \ldots \ldots \ldots \ldots \ldots \ldots \ldots \ldots \ldots \ldots \ldots \ldots$

M. Girardi, L. Weis

14. Chaotic zone in the Bogdanov-Takens bifurcation for diffeomorphisms $\ldots \ldots \ldots \ldots \ldots \ldots \ldots \ldots \ldots \ldots \ldots \ldots \ldots \ldots \ldots$

V. Gelfreich

15. Carleman estimates for a plate equation on a Riemann manifold with energy level terms . ............... 199

I. Lasiecka, R. Triggiani, P.F. Yao

16. Hyperbolicity for systems . ................ 237

T. Nishitani

17. Strictly hyperbolic operators and approximate

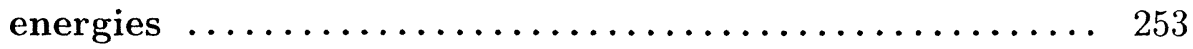

F. Colombini, D. Del Santo

18. Multiple highly oscillatory shock waves ........ 279 Y.-G. Wang

19. Exponential time decay solutions of Schrödinger equations and of wave equations in even dimensional spaces ...... 293

Y. Dan, K. Kajitani

20. Inverse scattering for a small nonselfadjoint perturbation of the wave equation $\ldots \ldots \ldots \ldots \ldots \ldots \ldots \ldots \ldots \ldots \ldots \ldots$

K. Mochizuki 


\section{Preface}

The 3rd International ISAAC Congress took place from August 20 to 25, 2001 in Berlin, Germany, supported by the German Research Foundation (DFG), the city of Berlin through Investitionsbank Berlin and the Freie Universität Berlin. 10 ISAAC Awards were presented to young researchers in analysis its applications and computation from all over the world on the basis of financial support from Siemens, Daimler Crysler, Motorola and the Berlin Mathematical Society and book gifts from Birkhäuser Verlag, Elsevier, Kluwer Academic Publisher, Springer Verlag and World Scientific.

The ISAAC is grateful to all these institutions, firms and publishers for their support. Due to the support from DFG and from Investitionsbank Berlin many of the 362 registrated participants could be financially supported. Unfortunately the financial supports were granted too late to reach more people from former $\mathrm{SU}$ as the procedere for visa is still more than cumbersome and embassies are not at all flexible. Hence, a big part of the financial support could not be used and had to be returned.

The 10 plenary lectures were

I. Antoniou, I. Prigogine (Intern. Solvay Inst. Phys. Chem., Brussels): Irreversibility and the probabilistic description of unstable evolutions beyond the Hilbert space framework (read by I. Antoniou), N.S. Bakhvalov, M.E. Eglit (Math. Mech. Dept., Lomonosov State Univ. Moscow): Homogenization of some multiparametric problems (read by M.E. Eglit),

A.D. Bruno (Keldysh Inst. Appl. Math., Moscow): Power geometry as a new calculus,

M. Essén (Dept. Math., Uppsala Univ.): Some results on $Q$ spaces, P. Kuchment (Texas A \& M Univ., College Station): Differential and pseudo-differential operators and graphs as models of mesoscopic systems,

V. Maz'ya (Dept. Math., Linköping Univ.): The Schrödinger and the relativistic Schrödinger operators on the energy space: boundedness and compactness criteria,

S. Nikols'kii (Steklov Inst. Math., RAS Moscow): Boundary problems 
and algebraic polynomials,

T. Nishitani (Dept. Math., Osaka Univ): Hyperbolicity for systems

S. Saitoh (Dept. Math., Gunma Univ.): Theory of reproducing kernels, M. Singer (Dept. Math., North Carolina State Univ., Raleigh, NC): Galois theory of linear differential equations with applications to Hamiltonian mechanics,

D. Tataru (Dept. Math., Univ. Cal., Berkely): The nonlinear wave equation.

In 38 sessions from real, complex and hypercomplex analysis, from potential theory, differential geometry, differential equations and operator theory, from mathematical physics, engineering and life sciences, and from numerical analysis and computation nearly 400 scientists from altogether 41 countries participated in the congress.

The abstracts of the plenary, the main and the regular talks can be found at the webpage of the "Atlas Mathematical Conference Abstracts" under

\section{http://at.yorku.ca/cgi-bin/amca/cahk-01}

ISAAC and the local organizers highly appreciated this service, on the basis of which the abstract booklet was easily produced. Thanks are due to Elliott Pearl from York University for his perfect arrangement of the abstracts.

The ISAAC Awards for young scientists in analysis its applications and computation were given to

Dr. Jin Chen, Professor at Fudan University in Shanghai, China: Inverse Problems,

Dr. Young-Bok Chung, Professor at the Chonnam National University in Kwangju, Korea: Complex Analysis of Several Variables,

Dr. Michael Dreher, Research Associate at the University of Tsukuba, Japan: Weakly Hyperbolic and Degenerate Parabolic Differential Equations,

Dr. Misolav Engliš, Researcher at the Academy of Sciences in Prague, Czech Republic: Quantization Methods on Manifolds and Invariant Differential Operators on Hermitean Spaces,

Dr. Vassili G. Gelfreich, Researcher at the Freie Universität Berlin, Germany: Dynamical Systems,

Dr. Maarten de Hoop, Professor at Colorado School of Mines in Golden, Colorado, USA: Wave Propagation and Scattering,

Dr. Frank Jochmann, Postdoc at the University of Leipzig, Germany: Partial Differential Equations of Mathematical Physics,

Dr. Alexey Karapetyants, Professor at the Autonomous University of Mexico D.F.: Bergman Spaces, Toeplitz Operators, and Singular Integral Operators, 
Dr. Vladislav V. Kravchenko, Professor at the National Polytechnic Institute in Mexico D.F.: Quaternionic Analysis and Partial Differential Equations of Mathematical Physics,

Dr. Ya-Yuang Wang, Professor at the Jiao Tong University in Shanghai, China: Nonlinear Partial Differential Equations, Shock Waves, and Geometric Optics.

The prices were equipped with DM 800 each and with several books. Two awardees not participating on the congress did only get the certificates. These can be viewed on the ISAAC homepage at FU Berlin under http://www.math.fu-berlin.de/rd/ag/isaac/publication.html The award committee consisted of H. Begehr, E. Brüning, Ju. Dubinskii, M. Essén, R.P. Gilbert, J. Kajiwara, I. Laine, I. Netuka, D.A. Tarzia, M.W. Wong, C.C. Yang. The ISAAC society will continue in encouraging young researchers in analysis, its applications and computation by awarding prices for high quality research at its international congresses.

The proceedings of the congress will be published in several volumes. This present volume contains some of the plenary (1 hour) and main (45 minutes) lectures Nonlinear problems are the main target of mathematical analysis and its applications today. Survey articles report on new methods either for quite general problems as e.g. the power geometry for as well algebraic as differential equations or homogenization methods to describe inhomogeneous material or for special involved physical processes like electromagnetic wave propagation in thin (molecular) structures the theory of differential equations in graph-structures. Decomposition of the Hilbert space of an arbitrary Hamiltonian into subspaces of decaying and of non decaying states is explained. There are two main areas within the contributions : complex analysis and hyperbolic partial differential equations. In complex analysis $Q$-spaces and $Q^{\#}$-spaces are reported on, hyperbolically convex functions forming a non-linear space are studied, applying value distribution methods the proximity of preimages of polygons are investigated. Moreover, value distribution is generalized to algebraically closed fields of characteristic p. Necessary and sufficient conditions for the validity of Riemann's hypothesis are given and the important theory of reproducing kernels are shown to be widely applicable. Analytic functions and functionals in several complex variable are investigated on the basis of a series of new norms.

Hyperbolicity and strong hyperpolicity is surveyed on for first order systems together with their Cauchy problem. This is also in the center of research on second order strictly hyperbolic operators, on the Schrödinger equation and the wave equation in different situations even without boundary conditions. Also inverse scattering problems are con- 
sidered. Other problems come from potential theory, harmonic analysis and dynamical systems.

The camera-ready manuscript of the volume in the Kluwer style was prepared by Barbara G. Wengel. She together with Daria Schymura, Astrid Begehr and Andreas Krausz were heavily involved with the congress organization. Thanks are due to them and to all the other helpers from both mathematical institutes of the FU Berlin among them in particular the dynamical systems group around Professor B. Fiedler (FU) and Dr. K.R. Schneider (WIAS).

The next international ISAAC Congress will take place at York University in Toronto from August 11 to 16, 2003. 